\title{
Desenvolvimento de dispositivo para captura de equipamentos com recepção Wi-Fi a fim de estimar a quantidade de passageiros em transporte público
}

\section{Caio V C dos Santos*, Vinicius O Civali, Madson C de Almeida, Flávio T Mariotto}

\section{Resumo}

Este projeto visa contabilizar os passageiros dentro de um ônibus, por meio da identificação de dispositivos com conexão wi-fi. Essa identificação ocorre através de um roteador operando em modo monitor, que detecta smartphones, notebooks e outros dispositivos que tentam acessar sua rede wi-fi, capturando seus Mac Address, uma identificação única de cada hardware eletrônico, aliado a um módulo GPS, que fornece a posição do ônibus em tempo real, possibilitando dados integrados da lotação do veículo com seu georeferenciamento. Tais dados são extremamente úteis para analisar itinerários, observando o tráfego de passageiros em cada ponto de ônibus, além de oferecer maior comodidade aos usuários, que saberão previamente a situação do ônibus em que pretendem embarcar.

\section{Palavras-chave: \\ Contagem de passageiros, Captura de Mac Address, Transporte Público.}

\section{Introdução}

A fim de melhorar o serviço de ônibus circulares internos da Unicamp, o Laboratório Vivo de Mobilidade Elétrica para Transporte Coletivo na Unicamp buscou implementar um sistema capaz de verificar a lotação dos ônibus circulares internos do campus de Campinas, bem como identificar a origem e destino de cada passageiro, de maneira mais barata, porém tão eficaz quanto as soluções existentes no mercado, as quais utilizam câmeras e sensores que encarecem o sistema.

Desta forma, foi desenvolvido um dispositivo capaz de realizar tais detecções por meio de um roteador wi-fi, baseado em soluções desenvolvidas na Universidade Federal de Santa Catarina ${ }^{1}$ e na Cidade de Madri ${ }^{2}$, para atuar, não só no caso específico da Unicamp, mas também em outros sistemas de transporte público.

Os dados obtidos, podem ser utilizados para reformulação de rotas, como também para complementar as informações ao usuário em aplicativos de mobilidade urbana.

\section{Resultados e Discussão}

A ideia do projeto é desenvolver um dispositivo para identificar equipamentos que disponham de conexão wifi, como smartphones e notebooks. Tais equipamentos procuram as redes wi-fi próximas, e enviam ao roteador um protocolo de comunicação, que contém, entre outros dados, uma identificação única de cada hardware, o Mac Address. Contudo, o roteador pode ser programado para entrar em modo monitor, em que ele deixa de fornecer acesso à rede para apenas registrar os protocolos de comunicação que chegam a ele.

Assim, neste projeto foi utilizado o roteador tp-link TL-MR3020 em modo monitor e com limitação do alcance, para diminuir a incidência de dispositivos fora do ônibus. Além disso, seu firmware foi modificado para o OpenWRT, a fim de possibilitar a instalação do Kismet, programa responsável por sincronizar a leitura dos Mac Address, com a informações de posicionamento georreferenciado fornecidas por um módulo GPS conectado à porta serial do roteador.

Por fim, há um modem $4 G$ conectado à porta USB, que é responsável por, periodicamente, enviar arquivos contendo a lista dos Mac Address criptografados, para preservar identidade dos passageiros, a posição do ônibus e o horário de leitura dos dados à um servidor, onde as informações são analisadas.

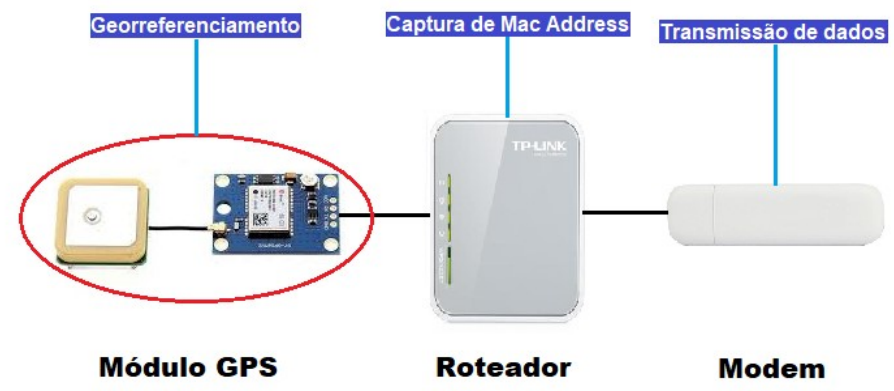

Figura 1. Desenho esquemático do projeto.

No servidor, é possível relacionar a quantidade de Mac Address detectados ao o número de passageiros no veículo, gerar uma matriz de tráfego de origens e destinos, bem como filtrar melhor os dados, através de um programa que identifique detecções de dispositivos que provavelmente estejam fora do veículo.

\section{Conclusões}

A estimativa de lotação de ônibus via detecção de Mac Address apresenta um ótimo custo-benefício, por ser bem mais barato que as soluções com câmeras e sensores, mas ainda consegue fornecer uma estimativa do número de passageiros e também a matriz de tráfego de origem-destino, que outras soluções não permitem.

Ademais, a solução é potencialmente melhor em regiões com mais usuários de smartphones, como ocorre no ambiente universitário.

\section{Agradecimentos}

Os autores gostariam de agradecer a CPFL, através do programa de P\&D da ANEEL no projeto PD-00063$3043 / 2018$, pelo suporte financeiro ao projeto.

1 Paradeda D. B.; Junior W. K.; Carlson R. C. ESTIMATIVA DE EMBARQUE E DESEMBARQUE DE PASSAGEIROS POR DETECÇÃO DE SINAL DE WI-FI DE DISPOSITIVOS MÓVEIS. 2018, 988-1000.

${ }^{2}$ Handte, M.; Foell S.; Wagner S.; Kortuem G. e Marrón, P. J. An Internetof-Things Enabled Connected Navigation System for Urban Bus Riders. IEEE INTERNET OF THINGS JOURNAL, VOL. 3. 2016, 735-744. 